\title{
Cultura e educação nos
} impérios ibéricos: pesquisa, teoria, experiência

Culture and education in the Iberian Empires: research, theory, experience

\author{
Antonio Cesar de Almeida Santos \\ Cláudio DeNipoti \\ Thais Nívia de Lima e Fonseca
}


Resumo: Este artigo apresenta o Grupo de Pesquisa Cultura e Educação nos Impérios Ibéricos (CEIbero) e comenta a sua produção historiográfica na última década, caracterizando o grupo, em seus eventos de divulgação científica e publicações, como espaço de discussão sobre os processos e as práticas educativas no ambiente político e cultural do Antigo Regime ibérico, particularmente no que se refere ao contexto de reformas educacionais realizadas sob influência das Luzes. Essa perspectiva está voltada para um entendimento mais abrangente do conceito de educação, para além da noção hegemônica na historiografia que a vê como educação necessariamente escolar, organizando as investigações em torno de três linhas de pesquisa: Administração, instrução e educação; Cultura escrita e práticas culturais e educativas; Instituições e práticas culturais e educativas. Neste sentido, as pesquisas conduzidas pelos integrantes do Grupo abordam a formação dos quadros administrativos dos Impérios ibéricos, os diversos projetos educacionais desses Impérios e suas relações com as atividades econômicas e profissionais, as relações entre a Ilustração e a cultura escrita, as práticas culturais e educativas como mediadoras de sociabilidades e as instituições de natureza cultural e educacional, seus componentes e suas ações.

Palavras-chave: Cultura; Educação; Ilustração.

Abstract: This article presents the Research Group on Culture and Education in the Iberian Empires (CEIbero) and comments Its historiographical production in the last decade, characterizing the group, in its scholar events and publications as a place for the discussion of the political and cultural environment of the Old Iberian regime, particularly in what reffers to the context of educational reforms carried out under the influence of the Enlightenment. This perspective is focused on a more comprehensive the concept of education, in addition to the hegemonic notion that sees education on in schools, organizing investigations around three lines of research: Administration, 
educational instruction; Written culture and cultural andeducational practices; Cultural institutions and practices and education. In this sense, the research conducted by the members of the Group approach the formation of the administrative staff of Iberian Empires, the several educational projects of these Empires and their relationship with economic and professional activities, such as relationships between Illustration and written culture, cultural practices as mediators of sociability and as cultural and educational institutions, their components and their actions.

Keywords: Culture; Education; Enlightenment. 
O Grupo de Pesquisa Cultura e Educação nos Impérios Ibéricos (CEIbero) (CEIBERO, 2020; CNPQ, 2020) tem sua origem no Colóquio 250 anos do ensino público no Brasil, realizado em 2009, na Faculdade de Educação da Universidade Federal de Minas Gerais. Tomando como ensejo os 250 anos do início das reformas pombalinas, o evento teve como principal objetivo reunir pesquisadores de diversas universidades brasileiras dedicados a temáticas de investigação que tivessem ligações diretas ou indiretas com a história da educação na América Portuguesa. Dessa reunião e de seus bons resultados, surgiu, em 2010, o Grupo de Pesquisa Cultura e Educação na América Portuguesa, denominação que vigorou até 2018 . ${ }^{4}$ Com o avanço das pesquisas e intercâmbios realizados por seus integrantes, os objetivos do Grupo foram estendidos para abranger, além de Portugal e seus domínios, o império espanhol, numa temporalidade mais alargada, entre o século XVI e as primeiras décadas do século XIX. A atual designação do CEIbero também decorre do interesse em agregar pesquisadores de países de língua espanhola que trabalham com temas correlatos aos que vêm sendo desenvolvidos. Atualmente, o Grupo congrega pesquisadores e estudantes de diversas instituições brasileiras (Universidade Federal de Minas Gerais, Universidade Federal de Ouro Preto, Universidade Federal dos Vales do Jequitinhonha e Mucuri, Pontifícia Universidade Católica de Minas Gerais, Universidade Federal do Paraná, Centro Universitário Curitiba, Universidade Estadual de Londrina, Universidade do Estado de Minas Gerais, Centro Universitário de Belo Horizonte, Universidade Federal de São João del Rei, Universidade do Estado do Pará, Universidade Federal do Maranhão) e colaboradores estrangeiros (Universidade de Lisboa, Universidade de Coimbra, Universidade de Torino, Escola Superior de Educação Jean Piaget [Almada/ Portugal]). Recentemente foram estabelecidos contatos com pesquisadores da Universidad Nacional de Luján, da Argentina, e da California State University, Los Angeles (EUA).

Nestes anos, o CEIbero vem se consolidando como espaço de discussão sobre os processos e as práticas educativas no ambiente político e cultural do Antigo Regime português, particularmente no que se refere ao contexto de reformas educacionais realizadas sob influência das Luzes. Seus Colóquios, realizados a cada dois anos, tem sido fundamentais para o diálogo e a articulação das pesquisas: em 2012, foi realizado o primeiro dos Colóquios, em Belo Horizonte (UFMG) e, desde então, o CEIbero esteve em Mariana (UFOP, 2014), Curitiba (UFPR, 2016) e Diamantina (UFVJM, 2018). As atividades do Grupo contam, desde 2010, com o fundamental suporte das agências de fomento, sobretudo 
CNPq, CAPES e FAPEMIG, por meio dos seus principais editais, como o Universal, Ciências Humanas, Programa Pesquisador Mineiro e Bolsa de Produtividade em Pesquisa. ${ }^{5}$ Por meio de seu planejamento de publicações, articulada aos Colóquios, o CEIbero tem promovido a edição de coletâneas e de dossiês temáticos em revistas científicas, com os trabalhos de seus integrantes e de outros pesquisadores participantes destes eventos.

\section{Fundamentos}

Quando de sua criação, o CEIbero considerou a importância e a necessidade de estudos que, de uma perspectiva renovada, enfocassem a cultura e a educação nas sociedades portuguesa e luso-americana do século XVIII. Essa perspectiva estaria voltada para o entendimento mais abrangente do conceito de educação, para além da noção hegemônica na historiografia que a vê como educação necessariamente escolar. Estudar as práticas e os processos educativos no contexto do Antigo Regime, anteriores ao surgimento dos sistemas escolares estatais no século XIX, exigia repensar a questão, uma vez que, naquele período histórico, a escola tal como a conhecemos hoje era ainda incipiente, e muitas outras experiências educativas eram até mais disseminadas, sobretudo na América portuguesa. Por isso essas experiências deveriam ganhar mais atenção dos pesquisadores, e as noções de práticas culturais e educativas poderiam ser entendidas como as "maneiras de fazer" utilizadas pelos diferentes sujeitos históricos em seus cotidianos, no que diz respeito às diferentes ações educativas postas em curso. Com a inspiração em autores como Pierre Bourdieu, Michel De Certeau e Roger Chartier, o CEIbero tem procurado discutir essa construção conceitual, entendendo as práticas educativas a partir do estabelecimento de estratégias, definidas como as "ações de grupos ou de indivíduos, de diferentes segmentos, relacionadas com as diversas esferas diferenciadas de poder, institucionalizado ou não”. Aos conceitos de práticas culturais, práticas educativas e estratégias, alia-se outro, "o de apropriação, que tem a sua operacionalidade demonstrada na análise das resultantes das práticas e das estratégias nos usos que os sujeitos fazem dos elementos que lhes permitem construir lugares e identidades" (FONSECA, 2009, p. 9-12).

A opção por essa concepção mais alargada de educação e da maior diversidade de experiências educativas na América portuguesa resulta, para o CEIbero, na necessidade da

[...] participação de pesquisadores dedicados ao estudo de 
diferentes campos, como história intelectual, política, eclesiástica, econômica e das práticas culturais, o que configura importante avanço historiográfico, por agregar essas dimensões em torno da discussão sobre a Ilustração e seus impactos no mundo lusoamericano (FONSECA; SANTOS, 2020, p. 9).

Os diferentes campos de pesquisa também se estruturam em torno do conceito cultura escrita, importante elemento articulador das experiências vivenciadas naquele contexto. Por isso, cultura escrita - ou culturas do escrito é outro conceito que subsidia as pesquisas conduzidas pelo CEIbero, conforme será apresentado mais adiante.

O CEIbero organiza-se em torno de três Linhas de Pesquisa: Administração, instrução e educação, Cultura escrita e práticas culturais e educativas e Instituições e práticas culturais e educativas. Neste sentido, os estudos conduzidos pelos integrantes do Grupo abordam a formação dos quadros administrativos dos impérios ibéricos, os diversos projetos educacionais desses impérios e suas relações com as atividades econômicas e profissionais, as relações entre a Ilustração e a cultura escrita, as práticas culturais e educativas como mediadoras de sociabilidades e as instituições de natureza cultural e educacional, seus componentes e suas ações. Além de abranger uma pluralidade de sujeitos, situados em diferentes estratos sociais, as pesquisas realizadas pelos integrantes do CEIbero vem enfocando as trajetórias de indivíduos de algum modo inseridos no contexto dessas práticas, os processos conduzidos por instituições educacionais, laicas ou religiosas, os usos da escrita e da leitura e as práticas educativas não escolares, abrangendo os diversos ambientes em que ocorrem práticas sociais socializadoras e educativas.

\section{As linhas de pesquisa}

Apresentamos a seguir algumas reflexões sobre a produção dos pesquisadores do CEIbero, no âmbito das três linhas de pesquisa que o constituem. Tais reflexões consideram os estudos que, muitas vezes, foram apresentados em primeira mão nos Colóquios e publicados nas coletâneas e dossiês temáticos organizados pelo Grupo. Pretendemos demonstrar como, a partir das historiografias de referência e da exploração de arquivos brasileiros e portugueses, esses pesquisadores têm contribuído para o avanço do conhecimento sobre a cultura e a educação na América portuguesa. 


\section{Administração, instrução e educação}

Esta Linha de Pesquisa está voltada para o estudo da difusão de ideias e práticas concernentes à formação de indivíduos comprometidos com os diferentes níveis (central, colonial/capitanias e municipal) e âmbitos (político, judicial, eclesiástico, militar, fazendário) da administração portuguesa, sendo discutidos seus projetos reformistas, ${ }^{7}$ com a identificação das conexões destes projetos com o ideário das Luzes. ${ }^{8}$ No geral, entende-se que o "Reformismo Ilustrado” português, que produziu diversas mudanças em todos os níveis de ensino, caracterizou-se, nesta área, por discussões de “conotação claramente política”. Deste modo, não obstante o desejo de superar um alegado atraso no ensino, provocado “pela falta de interesse na promoção das ciências”, as reformas pretendiam "formar súditos úteis ao Estado e afinados com um tempo de Luzes", produzindo indivíduos "familiarizados com as ciências e aptos a contribuir para o progresso da nação"; ou seja, as mudanças propostas e/ ou realizadas deveriam estar afinadas aos interesses da Coroa, garantindo “a conservação da sociedade e do Estado”. Este entendimento acerca das reformas educacionais da segunda metade do século XVIII, em Portugal, mostra a estreita vinculação entre projetos voltados para a formação intelectual dos jovens e as políticas propostas pela Coroa portuguesa. Estas políticas, por sua vez, expressavam algum tipo de vinculação com o ideário das Luzes, o qual chegava ao reino português por intermédio de diferentes indivíduos que pretendiam tornar corrente, naquela sociedade, “um pensamento racional e empírico”, nos moldes do que acontecia no restante da Europa (VILLALTA, 2011, p. 160-162, grifo do autor); ver também Araújo (2003).

A historiografia atenta às reformas educacionais considera que a finalidade delas foi a de introduzir em Portugal uma nova atitude diante da natureza e da sociedade. Sem dúvida, as ditas reformas pombalinas do ensino, que abrangeram a criação da Aula do Comércio (1759), a reforma dos Estudos Menores (1759), a criação do Colégio Real dos Nobres (1761) e os novos Estatutos da Universidade de Coimbra (1772), "testemunham um sério esforço destinado a implantar no ensino português certas modernidades que faziam carreira além-fronteiras” (COSTA; MARCOS, 2000, p. 125). Contudo, antes que as mudanças propostas para o ensino pudessem gerar a desejada nova mentalidade, a administração régia já utilizava uma série de práticas que indicam a adoção de novos modos de governar; por exemplo, a realização de levantamentos estatísticos e descrições geográficas deveria subsidiar as ações das autoridades coloniais, 
as quais também recebiam instruções que, em larga medida, buscavam estabelecer "um sistema político, civil e militar" que pudesse ser aplicado a toda a América portuguesa (SANTOS, 2016c). Nota-se, portanto, a importância em pesquisar a difusão de ideias e práticas que modificaram diversos aspectos da administração, no território europeu e na América (SANTOS, 2008). No que se refere aos efeitos das reformas dos estudos, especialmente da Universidade de Coimbra, devemos dirigir nosso olhar para as décadas finais do século XVIII, quando podem ser melhor identificadas e avaliadas a presença e a utilização de novos métodos e conhecimentos científicos (SANTOS, 2011).

Considerando estes aspectos gerais, os pesquisadores do CEIbero que atuam na linha de pesquisa Administração, instrução e educação tem focado seus estudos nas relações entre os saberes que circulavam no ambiente europeu do século XVIII e os conhecimentos e metodologias de ensino que se pretendeu adotar em Portugal. Nesta direção, Antonio Cesar de Almeida Santos tem discutido a proposta formulada pelos reformadores dos Estatutos da Universidade de Coimbra, cuja intenção foi a de substituir a escolástica jesuíta por um método “mais próprio para dar a conhecer as verdades pelas suas causas, para produzir as ciências nos entendimentos humanos e para gerar neles o espírito de exatidão e de ordem" (ESTATUTOS..., 1772, p. 23). Neste sentido, procura avaliar se, e em que medida, as reformas do ensino, não obstante óbvias motivações políticas, moviam-se prioritariamente por aspectos educacionais e se a intenção havia sido mesmo a de alterar uma situação na qual, “por motivos metodológicos fundamentais, a ciência ministrada na Universidade nada tinha de investigativa e tudo de argumentativa” (MAGALHÃES, 1997, p. 971, grifo do autor).

Eduardo Teixeira de Carvalho Júnior, outro integrante desta linha de pesquisa, também teve sua atenção voltada à metodologia do ensino e sua importância para a formação “de homens úteis à nação". Centrando sua atenção na obra Verdadeiro método de estudar, de Luiz Antonio Verney, e na polêmica que envolveu a sua recepção em Portugal em meados do século XVIII, pode afirmar que:

[...] o conceito de método, no caso específico de Portugal, foi utilizado para articular todo um conjunto de medidas necessárias a serem implementadas pelo reino, que pela sua amplitude, transcendiam o aspecto meramente educacional e apontavam para a necessidade de uma ampla renovação da cultura portuguesa (CARVALHO JÚNIOR, 2016, p. 21). 
Carvalho Júnior entende que "Verney defendia o projeto de um novo homem, um homem capaz de entender os interesses dos Príncipes para poder aconselhá-lo”, situação que exigia atenção para com a formação “dos jovens que futuramente iriam ocupar cargos de relevância na administração do reino”; para Verney, assinala, a educação precisava ser pensada como um assunto de Estado (CARVALHO JÚNIOR, 2016, p. 23, grifo do autor).

Como indicado, as propostas que visavam a reformar a mentalidade de setores da sociedade portuguesa conformavam-se a determinados aspectos do discurso da Ilustração. Neste sentido, Ana Cristina Araújo (2014, p. 276), pesquisadora do Grupo, ${ }^{9}$ afirma que diversos pensadores portugueses de meados do século XVIII estiveram “sob o signo de John Locke”, produzindo reflexões sobre “questões relativas ao método dos estudos, da instrução, da divulgação de conhecimentos úteis e da formação moral e religiosa da juventude”. A propósito, Verney criticava os estudos que se faziam em Portugal, pois eram conduzidos "sem método, sem razão, sem demonstração, e pela maior parte, por via de conjectura” (VERNEY apud CARVALHO JÚNIOR, 2016, p. 29), situação que deveria ser alterada, caso aquele pequeno reino almejasse igualar-se às demais nações cultas da Europa. Era preciso deixar de lado as certezas assentadas nas autoridades e buscar conhecer a realidade pela observação e pela experimentação, em sintonia com os pensamentos de Locke e Newton.

Contudo, como já apontado, se quisermos ter uma melhor visão dos resultados da reforma do ensino e, em particular, dos Estatutos da Universidade de Coimbra, é necessário olhar para o período pós-pombalino, para os reinados de D. Maria I e de D. João VI. Este entendimento é corroborado por diversos historiadores portugueses, como Carlos Moura Martins e José Damião Rodrigues. O primeiro, ao tratar do desenvolvimento de uma “cultura técnico-científica” em Portugal, considera que só após a década de 1780, ocorreu uma “aplicação prática do conhecimento" científico sobre o território, destacando, porém, a existência de uma fase de “preparação e de organização” das instituições responsáveis pela produção de tal conhecimento, o que teria ocorrido no "período final da governação pombalina (1770-1777)”. Percebe-se, nesta cronologia, a importância da reforma da Universidade de Coimbra, especialmente a criação e o funcionamento dos cursos de Matemática e de Filosofia Natural, cujos egressos foram aproveitados em “cargos da administração pública” (MARTINS, 2017, p. 245-247). De modo similar, José Damião Rodrigues (2017, p. 169) defende que “a literatura de carácter estatístico e memorialista que se produziu por iniciativa da Academia Real das Ciências [criada em 1779] e que se destinava a elaborar 
um diagnóstico do estado da monarquia com vista ao seu progresso económico, social, cultural e moral" foi resultado do "programa de formação" gestado no contexto da reforma universitária de $1772 .{ }^{1}$

Assim, ainda que, no terceiro quartel do século XVIII, não seja possível identificar a aplicação de conhecimentos técnico-científicos na administração portuguesa, nos moldes considerados por Martins e Rodrigues, verifica-se, naquele contexto, a existência de "preocupações estatísticas, de todos os matizes” (SANTOS, 2018, p. 340-341). Estas preocupações estão expressas em várias Instruções de governo, um tipo de documento voltado "à orientação de indivíduos que iriam ocupar cargos governativos e que, de algum modo, necessitavam de determinados tipos de conhecimento que os capacitassem para a execução das tarefas que lhes estavam sendo atribuídas”. Apesar das Instruções de governo existirem desde, pelo menos, o início da expansão, elas adquirem uma nova feição durante o reinado de D. José, à medida que são utilizadas para disseminar normas administrativas que a Coroa queria ver implementadas nos territórios sob seu domínio (SANTOS, 2016c, p. 39, 42).

Outros aspectos a destacar nas relações entre a administração, instrução e educação são as bibliotecas pertencentes a diversos governadores de capitanias da América portuguesa e os textos produzidos por eles, como indicam trabalhos de Laura de Mello e Souza e Fábio Kuhn, que participaram de Colóquios promovidos pelo CEIbero. Os governadores, em geral, dirigiam aos seus sucessores textos identificados como memórias ou instruções, nos quais "a utilização da experiência própria" servia "como elemento de uma pedagogia governativa que podia contribuir ao aperfeiçoamento dos servidores do Império" (SOUZA, 2020, p. 35). Quanto à posse de livros, avalia-se se eles poderiam ter exercido alguma influência na prática administrativa dos governadores e se estes, por conta das possíveis leituras, poderiam ser vistos como "ilustrados" (KUHN, 2016).

Retomando o tema da "intervenção do Estado na formação dos jovens portugueses" e sua relação com a formação de quadros para a administração, devemos fazer uma rápida menção à Aula de Comércio e ao Colégio Real dos Nobres. A primeira, revestida de inegável êxito, procurou oferecer uma formação profissional a indivíduos "que iriam atuar na administração régia, no comércio e em outras atividades econômicas". Considerando o conteúdo a ser ensinado na Aula de Comércio, é patente a presença de ideias advindas da Ilustração inglesa, "marcadas pela defesa do experimentalismo e do conhecimento utilitário". O ensino ali ministrado "deveria inculcar uma preocupação em associar as ações 
dos indivíduos com a utilidade pública, reafirmando preceitos que reforçassem sua conduta moral, ao mesmo tempo em que novas habilidades e competências eram desenvolvidas" (SANTOS, 2016b).

Por sua vez, mesmo que o Colégio Real dos Nobres não tenha alcançado igual sucesso, a sua criação indica o desejo de incutir nos jovens fidalgos conhecimentos que os tornassem mais próximos aos interesses da monarquia portuguesa. A proposta de criação do Colégio não foi uma inovação pombalina, pois Antonio Nunes Ribeiro Sanches, em suas Cartas sobre a educação da mocidade, já havia indicado que os jovens nobres portugueses deveriam ser instruídos em "colégios", como se fazia em outros reinos europeus. Para Ribeiro Sanches, uma escola deste tipo era extremamente benéfica, "não somente pela suma utilidade que tirará desta Educação a Nobreza, mas sobretudo o Estado e todo o povo" (SANCHES, 1922, p. 168-192).

Conforme a exposição que apresentamos, percebe-se, como também já vem sendo apontado pela historiografia, que as reformas educacionais de meados do século XVIII, em Portugal, buscaram estabelecer um controle estatal sobre as escolas, sobre os conteúdos a serem ensinados e sobre os métodos a serem empregados no ensino. Identifica-se ainda o desejo de que esses conhecimentos servissem aos propósitos da Coroa, estabelecendo uma expressiva relação entre a instrução e educação e a administração régia. Os estudos desta linha de pesquisa do CEIbero, notadamente os conduzidos por Antonio Santos e Carvalho Júnior, ao se preocuparem em apresentar e discutir a base epistemológica sobre a qual estiveram assentadas as reformas, tem demonstrado que, não obstante os diversos percalços, ocorreu uma notável vinculação entre o "reformismo ilustrado" luso e algumas ideias que faziam carreira nos demais estados europeus, especialmente ideias de cariz utilitário, mais próximas de um espírito reformista do que utópico (ver IM HOF, 1995; VENTURI, 2003). Este aspecto utilitário é perfeitamente identificado quando se relaciona os fundamentos da política pombalina com os conteúdos que deveriam ser ensinados e os métodos que deveriam ser empregados (ver SANTOS, 2011).

\section{Cultura escrita e práticas culturais e educativas ${ }^{11}$}

Esta Linha de Pesquisa tem seu olhar centrado sobre o período final do século XVIII e início do século XIX no mundos ibérico e ibero-americano, em função do impacto gerado pelos processos reformistas pombalino e bourbônico, ambos com ênfase sobre o controle da palavra impressa tanto através da censura quanto 
pelo uso sistemático da imprensa para difundir e disseminar suas próprias “agendas” (TAVARES, 1999). ${ }^{12}$ Partindo de uma noção de cultura expressa como “a que articula as produções simbólicas e as experiências estéticas subtraídas às urgências do cotidiano, com as linguagens, os rituais e as condutas, graças aos quais uma comunidade vive e reflete sua relação ao mundo" (CHARTIER, 2010, p. 16) e de uma ideia de escrito definido como "todo e qualquer evento ou prática que tenha como mediação a palavra escrita”, fazendo valer a duplicidade semântica entre "escrita” e "do escrito" e aprofundando a noção de que não há homogeneidade na compreensão da cultura escrita em sociedades complexas (GALVÃO, 2010, p.219), busca-se compreender os diferentes agentes e as diferentes práticas envolvidas nos processos de escrita. Nesta direção, temos realizado percursos de pesquisa em busca da presença, impacto, necessidade ou interferência da palavra escrita - impressa ou manuscrita - nas instituições de poder, nas estruturas de comércio e nas formas de sociabilidade letrada ou científica na América ibérica em seus pontos de contato com as sedes imperiais.

Estabelecidas estas delimitações, os estudos feitos nessa linha abordam o circuito de comunicação da cultura escrita impressa (DARNTON, 2002) desde seu ponto de partida da escrita, buscando livros e autores que provocaram impactos ou mudanças em práticas culturais, como, por exemplo, o processo “de constituição do sujeito infantil moderno", a partir de livros que discorrem sobre os cuidados relativos à infância (RIPE; AMARAL, 2017). No outro extremo do circuito, a leitura foi abordada na perspectiva criada por Daniela Moscato, perseguindo leitores viajantes europeus no Brasil do século XIX e as pistas de suas leituras das obras de outros viajantes, naturalistas luso-brasileiros, do século anterior. Também explorou diversas outras formas de contato entre esses dois grupos, através da "participação em uma rede de sociabilidade científica que permitiu o acesso dos autores do século XIX às memórias científicas dos luso-brasileiros e, em determinados momentos, o contato direto com esses sujeitos", que constituíram uma “comunidade de leitores”, com práticas culturais compartilhadas quanto à leitura e à ciência (MOSCATO, 2017, p. 9). Entre esses dois extremos (escrita e leitura) situam-se diversos processos, geridos por "agentes" da cultura escrita, particularmente da imprensa, que têm sido estudados por sua capacidade de esclarecer aspectos dessa cultura no passado.

A participação dos leitores nas práticas culturais resultantes pode ser estudada nas formas como ideias e livros foram apropriados por distintas camadas e indivíduos, em um espectro que inclui práticas educativas e formas de leitura 
escolar ou pedagógicas, interpretações mediadas pela política (pensemos nas inconfidências) ou práticas profissionais variadas nas quais a leitura visa a objetivos práticos - como plantar, construir algo etc. -, sem esquecer questões religiosas constantemente presentes no mundo ibérico do século XVIII.

Dentre essas delimitações, fica patente a relevância, no contexto enfocado, dos tradutores portugueses para a difusão (ou combate) das ideias iluministas, que só pode ser comparável com a atuação dos censores no mesmo campo (DENIPOTI, 2017a, 2019a; DENIPOTI; FONSECA, 2011). Além disso, as traduções para a língua portuguesa influenciaram o mercado editorial, e possibilitam buscar compreender como se deu o estabelecimento de uma norma culta da língua portuguesa em fins do século XVIII (DENIPOTI, 2018a; HARDEN, 2018). De forma semelhante, os livreiros desempenharam um papel fundamental como agentes da palavra escrita e das ideias contidas nos livros, sendo também frequentemente associados à subversão que tais ideias promoviam. Foi o caso de Diogo Borel que, como a maioria dos livreiros em Lisboa na segunda metade do século XVIII, nascera na França e emigrara para Portugal. Em 1792 ele foi denunciado pelo embaixador português em Paris ao Intendente de polícia de Lisboa por ter supostamente mandado imprimir uma tradução portuguesa da constituição revolucionária de 1791. O processo de investigação resultante, com a prisão de Diogo Borel e seu irmão, ajudam a perceber as práticas culturais em jogo (DENIPOTI, 2014, 2018b). Também o livreiro e impressor francês radicado em Lisboa Francisco Rolland contribuiu para a difusão de ideias em torno de questões fundamentais para as Luzes - a utilidade, a necessidade, a instrução e o serviço ao império -, ao mesmo tempo que habilmente navegava nos espaços portugueses de sociabilidade letrada como mediador comercial e cultural (DENIPOTI, 2017b).

O livro como instrumento educacional também está no centro de diversos debates levados a cabo pelo CEIbero, em especial por estudos de Justino Magalhães (2011, 2018), professor do Instituto de Educação da Universidade de Lisboa. Ao pensar uma historicidade do livro educacional, este pesquisador tem a rara oportunidade entre os historiadores de definir os parâmetros de um campo de estudos:

Fazer a história do manual escolar é indagar da génese, natureza, simbolização e significação mais profundas do saber e do conhecimento; é indagar da materialidade e da significação do(s) livro(s) como texto, enquanto ordem (suporte e unidade) do saber e do conhecimento; é indagar, ainda, do livro como discurso 
(configuração, forma/estrutura, especialização, autoria); é, por fim, indagar do saber como conhecimento e do conhecimento como (in)formação (MAGALHÃES, 2018, p. 6).

Outras faces da cultura escrita transparecem na infinita quantidade e no uso variado do manuscrito nessas sociedades, desde o vasto volume de documentos produzidos para a administração dos territórios compreendidos na ideia de “império” - incluindo aí o universo dos escritos jurídicos (petições, processos, sentenças etc.) - até as "escritas de si” presentes na epistolografia e em outras formas de escrito, incluindo aqueles condenados como "subversivos" da ordem instituída (LEITÃO, 2016). Esses diversos tipos de manuscritos marcaram (provavelmente) mais indivíduos das bases da sociedade do que os documentos impressos tão zelosamente patrulhados pelas diversas instâncias de poder, em especial se considerarmos o caráter de oralidade presente nessa escrita; ou seja, o quanto desses manuscritos resultam da verbalização de seus desejos, demandas e necessidades, anotados por outros indivíduos para inclusão no universo escrito (VARTULI, 2014).

Esse conjunto de estudos mantém em mente diversos pressupostos metodológicos fundamentais, que complementam as questões iniciais expostas acima. Preliminarmente, ao tipificar uma cultura, busca-se limitar sua polissemia, ao mesmo tempo em que se multiplicam suas categorias taxonômicas e os campos de estudos. São classificações que levam em conta o público ao qual se destina ou que fomenta a cultura (de massas, popular ...), que pensam o suporte de transmissão do conhecimento (escrita, oral, midiática ...), ou mesmo que designa um movimento, uma ação de oposição contra a própria cultura ou a um tipo de cultura (contracultura, cultura marginal ...). Em torno desses tipos tende-se a constituir nichos de pesquisa, com suas metodologias e problemas, mais ou menos originais. Também, ao se pensar a cultura do escrito, busca-se evidenciar a dimensão de difusão de um conhecimento especializado (a escrita) como parte de uma cultura, de um processo de cultivo. A cultura do escrito pressupõe o que já não existe mais, o acontecimento passado representado pelo escrito, a memória redigida e rememorada pelo "culto" ao passado e ao próprio escrito. Tal dimensão de culto se revela não apenas na valoração dos escritos sagrados, mas também no reconhecimento dos livros como substrato do saber e objetos de distinção social atrelados aos letrados, aos sacerdotes, aos detentores de um saber especializado. Um "saber passado" que também é atualizado e projetado pelo ato do cultivo, pela difusão visando um 
futuro que constitui um dos propósitos da educação. Mais do que categorizar um tipo de cultura (a escrita) em função de outra (a oral) - seja na sua negação, seja na sua complementaridade afirmativa -, o termo cultura do escrito visa, portanto, explicitar os processos de difusão de conhecimento que envolvem a escrita em suas diversas formas simbólicas e materiais, espaços geográficos, agentes e lugares de cultivo da escrita. ${ }^{13}$ É o caso, por exemplo, do estudo de Chistianni Morais (2009) que buscou analisar a posse, os usos e a disseminação da cultura escrita, bem como a difusão da escola entre os anos de 1750 a 1850, em Portugal e no Brasil, especialmente na Vila de São João del-Rei.

Enfatiza-se, assim, que, nos debates e esforços do CEIbero, interessam escritas de império, ou seja, aquelas produzidas e/ou consumidas na vastidão geográfica dos impérios ibéricos e na amplitude temporal de um século XVIII expandido, naquilo que se pode chamar, como forma de suscitar debates, de ruptura do Antigo Regime. Se, na última década, o foco central dos estudos realizados pelo Grupo foi o âmbito luso-brasileiro deste recorte, a recente ampliação do espectro de investigação para todo o espaço ibérico e iberoamericano pretende aprofundar investigações, leituras e debates sobre a Ilustração em Portugal, Espanha e suas colônias tendo como alvo a extensão dos resultados obtidos até o momento para um espaço mais amplo sem, porém, tentar meramente comparar experiências distintas na península ibérica ou em suas colônias, mas de buscar experiências singulares em torno da cultura escrita e alcançar, através delas, os diversos significados que as Luzes assumiram e que tem provocado análises historiográficas de diferentes matrizes.

\section{Instituições e práticas culturais e educativas}

A educação na América portuguesa no século XVIII apresenta peculiaridades, naquela época menos identificada à ideia de escola do que em nossos tempos. Mesmo para as práticas educativas de tipo escolar, a pesquisa demanda abordagens que considerem diferenças com o processo de escolarização que se observou a partir da instalação do Estado independente. Ambas, no entanto, tinham em comum a concepção predominante acerca da educação como instrumento de construção da civilidade. Esse é o ponto central na orientação das investigações cujo objeto é a educação no período colonial, e está presente nas práticas de diferentes instituições que, de algum modo, estiveram envolvidas com a educação. Além disso, é importante também determinar a relação entre as instituições e suas práticas educativas, e os lugares sociais ocupados por seus 
sujeitos, particularmente os professores e os estudantes. Analisar a questão das instituições educativas na América portuguesa sob essas perspectivas é o objetivo principal dessa linha de pesquisa, que começa também a investigar o tema nos territórios espanhóis da América.

Os estudos desenvolvidos nesta Linha dePesquisa consideram principalmente as escolas (estatais, eclesiásticas, privadas), as instituições religiosas leigas e eclesiásticas (irmandades e ordens terceiras, conventos e recolhimentos), a família, instituições militares, além de incluir experiências educativas ocorridas fora de ambientes institucionais mas igualmente marcados por processos e métodos definidos por uma tradição prática ou por fundamentos teóricos. Sejam quais forem os temas, faz-se necessário, antes de tudo, refletir sobre as concepções de educação correntes na Europa e, particularmente, no mundo luso-americano do século XVIII. Um dos problemas presentes em boa parte da historiografia da educação tem sido o de entendê-la predominantemente como educação escolar, tomando como referência o formato e a estrutura da escola e dos sistemas escolares surgidos a partir do século XIX. Com isso, as modalidades de educação nos períodos anteriores acabam sendo vistas sob esse prisma, o que compromete o entendimento das peculiaridades das diversas formas de educação possíveis, inclusive aquelas que ficariam mais identificadas ao universo escolar, como o aprendizado da leitura e da escrita.

Ao se debruçarem sobre as concepções de educação presentes no contexto do Antigo Regime, especialmente em Portugal e no Brasil, os pesquisadores do CEIbero tem contribuído para esclarecer a historicidade dos processos e das práticas educativas efetivas naquelas sociedades. Estudos específicos sobre essa temática de caráter mais conceitual tem sido realizados por Thaïs Nívia de Lima e Fonseca, e aplicados por outros pesquisadores em seus objetos particulares de investigação. ${ }^{15}$ Tais instrumentos conceituais são fundamentais para a análise dos registros documentais ao permitir leituras sobre as intenções, as estratégias e até os resultados das ações voltadas para a educação dos indivíduos, registros não raros opacos, sobretudo quando se tratam de dimensões educativas mais distantes daquelas de natureza escolar.

A retomada de um tema considerado clássico na historiografia da educação colonial foi necessária para balizar a discussão sobre as características escolares e não escolares da educação no Brasil setecentista: as reformas da educação iniciadas pelo Marquês de Pombal, em 1759, no reinado de D. José, e continuadas nos reinados de D. Maria I e D. João VI. Por meio de uma abordagem crítica da interpretação mais conhecida - acerca do fracasso das reformas e dos prejuízos 
causados à educação no Império português pela expulsão da Companhia de Jesus e fechamento de suas escolas -, pesquisas recentes tem colocado em questão essa visão homogeneizadora das reformas e seus efeitos. Os estudos de Thaïs Nívia de Lima e Fonseca (2009, 2010, 2011, 2014, 2016c, 2019a, 2020) tem discutido a implantação das reformas na Capitania de Minas Gerais, onde não havia escolas ou qualquer instalação dos jesuítas ou de outra ordem religiosa. A implantação das aulas régias nesta região, ainda que não tenha resultado em um sucesso absoluto, não foi despercebido e acabou ajudando a desenvolver demandas sociais pela educação de caráter escolar oferecida pelo Estado. A atenção dada aos professores régios e seus lugares sociais tem ajudado na reflexão pretendida pelos pesquisadores do CEIbero sobre o papel da educação e da instrução na busca por distinção, conforme as estruturas sociais e os valores culturais predominantes no Antigo Regime luso-americano.

Os avanços têm sido significativos no campo de estudos das estratégias familiares para a educação de descendentes e herdeiros, de diferentes segmentos sociais, das elites econômicas aos grupos menos favorecidos. Os trabalhos de Kelly Lislie Julio (2017), Fabrício Vinhas Manini Angelo (2017) e Talitha Maria Brandão Gorgulho (2020) analisaram particularmente essa questão, e demonstraram as relações estreitas entre os capitais econômico e cultural e as estratégias educativas adotadas por famílias dos setores intermediários e das elites econômicas da Capitania de Minas Gerais. Esses pesquisadores inovaram ao trazerem os aportes teóricos de Pierre Bourdieu para o estudo de estratégias educativas na sociedade luso-americana setecentista, e promoveram importante interlocução com referências metodológicas da história social e da história demográfica, fundamentais para a análise do rico manancial de dados advindos das fontes utilizadas, os inventários post mortem e os testamentos, principalmente. Essas fontes, já familiares a boa parte dos pesquisadores do período colonial, só recentemente tem sido incorporadas aos estudos de história da educação, e o CEIbero tem se mostrado pioneiro neste aspecto. Todos esses trabalhos têm também se destacado pela interlocução com os estudos sobre as culturas do escrito, uma vez que analisam parte do capital cultural das famílias investigadas a partir de suas relações com a escrita. Posse de livros e produção escrita particular são objeto da atenção dos pesquisadores, ${ }^{16}$ e suas análises têm partido das propostas metodológicas desenvolvidas por Justino Magalhães (1994). O estudo das assinaturas, presentes sobretudo nos inventários, testamentos e outros documentos de natureza notarial, ajudam a esclarecer os possíveis níveis de letramento dos indivíduos pesquisados e sua relação com 
as culturas do escrito. Neste ponto, as pesquisas do CEIbero tem construído um fértil diálogo com o campo dos estudos sobre letramento e alfabetização, já consolidado no campo da Educação.

A Linha de Pesquisa Instituições e práticas educativas e culturais tem tido particular interesse nas instituições ligadas direta ou indiretamente à Igreja. Conventos e recolhimentos, irmandades leigas e ordens terceiras, seminários, congregações e ordens religiosas são objeto de pesquisa de alguns de seus integrantes. Permanecem aqui os fundamentos da reflexão geral adotada de enfatizar a polissemia do termo educação, a fim de evidenciar a diversidade das práticas educativas presentes na sociedade colonial. As concepções mais convencionais de educação, associadas a práticas escolares, são naturalmente mais visíveis quando se trata de estudar algumas instituições que claramente tinham propósitos educativos, como é o caso dos seminários e, em parte, de conventos e recolhimentos. Sem deixar de mencionar, é claro, as ações de catequese levadas a termo por algumas ordens religiosas, com propósitos claramente educativos. Nesta área de pesquisa, destacam-se os estudos de Ana Cristina Pereira Lage (2013, 2014, 2019a), nos quais se entrelaçam referências à história das mulheres, história das instituições religiosas e estudos sobre letramento, para a análise das práticas educativas presentes nos conventos e recolhimentos da América portuguesa.

Embora o estudo das instituições de caráter confessional seja um campo já consolidado na historiografia, os pesquisadores do CEIbero tem contribuído para inserir a discussão de um ponto de vista mais específico, a partir de uma abordagem conceitual sobre a educação historicamente situada, ${ }^{18} \mathrm{o}$ que permite ir além das características estritamente escolares. Com isso, tem sido obtidos resultados promissores, no sentido de se perceberem, no interior daquelas instituições, práticas cotidianas inscritas no que poderíamos considerar um "projeto pedagógico" mais amplo, voltado para a educação formativa do cristão exemplar, do súdito fiel, e da inculcação dos valores mantenedores das estruturas e das hierarquias sociais vigentes. Também se percebem as apropriações de valores no movimento dos entrecruzamentos culturais, como é o caso dos estudos sobre processos educativos não escolares presentes em associações religiosas leigas e nas práticas desenvolvidas pelo clero regular na catequese de índios. Os estudos conduzidos por Itacir Marques da Luz (2014) e Jane Elisa Otomar Buecke (2019) são exemplares neste sentido.

Recentemente, uma nova dimensão institucional tem sido considerada no âmbito das pesquisas do CEIbero, voltada para estudos sobre as práticas 
educativas e instrução militar, desenvolvidos por Francis Albert Cotta Formiga $(2019,2020)$. Neste caso, cabe tanto discutir as características da educação e da instrução militares de caráter escolar, quanto as práticas educativas disseminadas no cotidiano de funcionamento das instituições militares coloniais, em consonância com os princípios pedagógicos, políticos e filosóficos correntes no Antigo Regime ibérico e ibero-americano.

\section{Entrelaçamentos}

Não obstante sua organização assentar-se nas três Linhas de Pesquisa acima identificadas, o CEIbero trabalha de forma articulada e integrada, fazendo com que os estudos desenvolvidos por seus pesquisadores se relacionem, promovendo importante diálogo entre os seus focos predominantes. Os trabalhos sobre as instituições, os processos administrativos e a cultura escrita trazem todos elementos uns dos outros, e todos se organizam sob a perspectiva dos processos e das práticas educativas em sentido amplo.

Recentemente, o Grupo tem investido, coletivamente, em investigar os usos sociais do vocabulário português do contexto da Ilustração, com a finalidade de construir uma melhor compreensão daquela sociedade. Com o projeto Glossário de termos do mundo ibérico setecentista (CEIBERO, 2018), já foram explorados alguns termos, como civil/civilizar/civilização (SANTOS, 2019b), disciplina (militar) (FORMIGA, 2020), educação/instrução (FONSECA, 2019b), letrados (SANTOS, 2019c), método (CARVALHO JÚNIOR, 2019), opinião pública (ARAÚJO, 2019) e útil/utilidade (DENIPOTI, 2019b). No desenvolvimento destes estudos, consideramos a hipótese de que o vocabulário de uma determinada sociedade possibilita o acesso à sua "realidade histórica", uma vez que os documentos produzidos permitem identificar e discutir como agentes da palavra escrita compartilharam sentidos comuns a determinados termos, utilizando-os como definidores de discursos e de práticas culturais. A abordagem utilizada adota a perspectiva de apreendermos como diversos agentes empregam o vocabulário da época em seus textos, ${ }^{19}$ levando em conta o contexto de produção, a função e a recepção contemporânea desses mesmos textos. Neste sentido, adotando pressupostos da História dos conceitos, como preconizada por Reinhart Koselleck, e do Contextualismo linguístico de Quentin Skinner, consideramos as temporalidades e as relações que produzem os sentidos das palavras, atentando para "quem fala, em que contexto e com qual intencionalidade" (MOLANO VEGA, 2015, p. 170). Estamos, portanto, elaborando um conjunto de 
estudos sobre os usos dados a determinadas palavras nas argumentações que ocorriam no contexto das Luzes portuguesas (ver SANTOS, 2019a).

O entrelaçamento de estudos do CEIbero com os de outros pesquisadores fica evidenciado nas estratégias editoriais do Grupo, como a organização de obras coletivas derivadas dos diversos Colóquios já realizados, como foi o caso das coletâneas Ilustração, cultura escrita e práticas culturais e educativas (SANTOS, 2016a), Cultura e educação na América Portuguesa (FONSECA; SANTOS, 2020) e Instituições educativas: cultura, escrita e administração na América Portuguesa [Estúdio Texto, 2020 - no prelo]. Na mesma direção, o CEIbero também tem publicado dossiês em revistas especializadas, a saber: Cultura e educação na América portuguesa [e-hum,v.5, n. 2, 2012]; Cultura escrita, educação e instrução no Antigo Regime português [História: Questões \& Debates, n. 60, 2014]; As formas e as funções escritas da palavra no Antigo Regime luso-brasileiro [Revista de História Regional, v. 19, n. 2, 2014]; Instituições, práticas educativas e Ilustração no mundo ibero-americano (séculos XVIII-XIX) [Educação em Revista, v. 32, n. 3, 2016]; Cultura e educação na América portuguesa [Revista de História e Historiografia da Educação, v. 3, n. 7, 2019].

Para encerrar este texto de apresentação do Grupo de Pesquisa Cultura e educação nos impérios ibéricos convidamos à leitura dos textos de alguns de nossos pesquisadores incluídos nesta seção da Antíteses. Os artigos, permitirão ao leitor um olhar sobre a prática historiográfica do Grupo, que está informada pelas considerações teóricas acima apresentadas. Enfim, e como já indicamos, o conjunto destes trabalhos mostra como os temas relativos à cultura escrita, aos processos administrativos e às instituições culturais e educacionais estão organizados sob uma perspectiva comum, a dos processos e das práticas educativas em sentido amplo. Boa leitura.

\section{Referências}

ANGELO, Fabrício Vinhas Manini. Para o meu filho se educar: o papel da família na longevidade educacional das gerações seguintes na Minas de Ouro (c. 1710 - 1760). 2017. Tese (Doutorado em Educação) - Universidade Federal de Minas Gerais, Belo Horizonte, 2017.

ARAÚJO, Ana Cristina (coord.). O Marquês de Pombal e a universidade. Coimbra: Imprensa da Universidade, 2000.

ARAÚJO, Ana Cristina. A cultura das luzes em Portugal: temas e problemas. Lisboa: 
Livros Horizonte, 2003.

ARAÚJO, Ana Cristina. Cultivar a razão, educar e civilizar os povos: a filosofia das Luzes no mundo português. Revista de História Regional, Ponta Grossa, v.19, n. 2, p. 263-281, 2014.

ARAÚJO, Ana Cristina. Opinião pública. Glossário de termos do mundo ibérico setecentista. 2019. Disponível em: https://denipoti.wixsite.com/website. Acesso em: 15 mar. 2020.

ANTUNES, Álvaro de Araújo. Alumiações, razões e críticas: José Bonifácio de Andrada e Silva e o plano de reforma da Faculdade de Filosofia da Universidade de Coimbra. In: SANTOS, Antonio Cesar de Almeida (org.). Ilustração, cultura escrita e práticas culturais e educativas. Ponta Grossa: Estúdio Texto, 2016, p. 185205.

BUECKE, Jane Elisa Otomar. Infância e práticas educativas na Amazônia seiscentista. 2019. Dissertação (Mestrado em Educação) - Universidade Estadual do Pará, Belém, 2019.

CARVALHO JÚNIOR, Eduardo Teixeira de. Método. Glossário do mundo ibérico setecentista. 2019. Disponível em: https://denipoti.wixsite.com/website/sobre-2. Acesso em: 30 jul. 2019.

CARVALHO JÚNIOR, Eduardo Teixeira de. Formar homens úteis à nação: o projeto verneyano e o ideário reformista português. COLÓQUIO CULTURA E EDUCAÇÃO NA AMÉRICA PORTUGUESA, 3., 2016, Curitiba. Anais [...]. Curitiba: [s. n.], 2016. Disponível em: https://coloquioceap.files.wordpress.com/2018/02/ iiic2ba-cceap-anais-do-evento.pdf. Acesso em: 14 mar. 2020.

CEIBERO. Cultura e Educação nos Impérios Ibéricos. Glossário de termos do mundo ibérico setecentista. 2018. Disponível em: https://denipoti.wixsite.com/ website. Acesso em: 2 fev. 2020.

CEIBERO. Cultura e Educação nos Impérios Ibéricos. Grupo Ceibero. [Minas Gerais]: Ceibero, 2020. Disponível em: https://ceibero.wordpress.com/. Acesso em: 2 fev. 2020.

CHARTIER, Roger. "Escutar os mortos com os olhos”. Estudos avançados. São Paulo, v.24, n.69, p. 6-30, 2010.

CNPQ - CONSELHO NACIONAL DE DESENVOLVIMENTO CIENTÍFICO E 
TECNOLÓGICO. Grupo de pesquisa: CEIbero - cultura e educação nos impérios ibéricos. 2020. Disponível em: http://dgp.cnpq.br/dgp/espelhogrupo/33062. Acesso em: 2 fev. 2020.

COSTA, Mário J. de Almeida; MARCOS, Rui de F. Reforma pombalina dos estudos jurídicos. In: ARAÚJO, Ana Cristina (coord.). O Marquês de Pombal e a universidade. Coimbra: Imprensa da Universidade, 2000. p. 97-125.

DARNTON, Robert. What is the history of the books. In: FINKELSTEIN, David; McCLEERY (ed.). Book history reader. New York: Routledge, 2002. p. 10-26.

DENIPOTI, Cláudio. O embaixador: o livreiro e o policial: circulação de livros proibidos e medo revolucionário em Portugal na virada do século XVIII para o XIX. Varia Historia, Belo Horizonte, v. 30, n. 52, p. 129-150, 2014.

DENIPOTI, Cláudio. Em busca da tradução perfeita: os discursos de tradutores e censores portugueses na segunda metade do século XVIII. In: SANTOS, Antonio Cesar de Almeida (org.). Ilustração, cultura escrita e práticas culturais e educativas. Ponta Grossa: Estúdio Texto, 2016, p. 89-106.

DENIPOTI, Cláudio. Tradutores médicos e a ideia de tradução em Portugal em fins do século XVIII: o caso dos livros de medicina. História; ciência, saúdeManguinhos, Rio de Janeiro, p. 913-931, 2017a.

DENIPOTI, Claudio. O livreiro que prefaciava (e os livros roubados); os prefácios de Francisco Rolland e a circulação de livros no Império Português ao fim do século XVIII. História: Questões \& Debates, Curitiba, v. 65, p. 385-411, $2017 \mathrm{~b}$.

DENIPOTI, Cláudio. O “y”, o artigo e as ortografias: a censura e o vernáculo português do século XVIII. Revista Brasileira de História, São Paulo, v. 38, n. 77, p. 37-55, 2018a.

DENIPOTI, Cláudio. Historiadores citando historiadores: afirmações de verdades e a construção do discurso histórico (Diogo Borel e as traduções da Constituição francesa). Praticas da Historia, Lisboa, n. 7, p. 133-160, 2018 b.

DENIPOTI, Cláudio Luiz. Escrita, Luzes, Nação e Império nos textos e paratextos de escritores e tradutores luso-brasileiros no século XVIII. História, São Paulo, v. 38, p. 1-20, 2019a.

DENIPOTI, Cláudio Luiz. Útil/utilidade. In: Glossário de Termos do Mundo Ibérico Setecentista, 2019b. Disponível em: https://denipoti.wixsite.com/website. Acesso 
em: 15 mar. 2020.

DENIPOTI, Cláudio; FONSECA, Thaïs Nivia de Lima. Censura e mercê - os pedidos de leitura e posse de livros proibidos em Portugal no século XVIII. Revista Brasileira de História da Ciência, Rio de Janeiro, v. 4, n. 2, p. 139-154, 2011.

DENIPOTI, Cláudio; PEREIRA, Magnus Roberto de Mello. O agradável serviço a D. João: as dedicatórias da Casa Literária do Arco do Cego (1799-1801). In: FONSECA, Thaïs Nívia de Lima; SANTOS, Antonio Cesar de Almeida (org.). Cultura e educação na América portuguesa. Belo Horizonte: Editora UFMG, 2020. p. 117-144.

ESTATUTOS da Universidade de Coimbra. Lisboa: Na Regia Officina Typografica, 1772. Livro Primeiro.

FONSECA, Thaïs Nívia de Lima. Letras, ofícios e bons costumes: civilidade, ordem e sociabilidades na América portuguesa. Belo Horizonte: Autêntica, 2009.

FONSECA, Thaïs Nívia de Lima. O ensino régio na capitania de Minas Gerais. Belo Horizonte: Autêntica, 2010.

FONSECA, Thaïs Nívia de Lima (org). As reformas pombalinas no Brasil. Belo Horizonte: Mazza Edições: FAPEMIG, 2011.

FONSECA, Thaïs Nívia de Lima. Educação na América Portuguesa: sujeitos, dinâmicas, sociabilidades. História. Questões \& Debates, Curitiba, v. 60, p. 15-38, 2014.

FONSECA, Thaïs Nívia de Lima. Writings and representations of education in Portuguese America. Sisyphus - Journal of Education, Lisboa, v. 4, p. 98-119, 2016 a.

FONSECA, Thaïs Nívia de Lima. Circulação e apropriação de concepções educativas: pensamento ilustrado e manuais pedagógicos no mundo lusoamericano colonial (séculos XVIII-XIX). Educação em Revista, Belo Horizonte, v. 32, p. 167-185, 2016b.

FONSECA, Thaïs Nívea de Lima. Circulação e apropriação de concepções educativas no mundo lusoamericano colonial. In: SANTOS, Antonio Cesar de Almeida (org.). Ilustração, cultura escrita e práticas culturais e educativas. Ponta Grossa: Estúdio Texto, 2016c.

FONSECA, Thaïs Nívia de Lima. História da educação em Minas Gerais: da colônia 
à república. Uberlândia: EDUFU, 2019a.v. 1.

FONSECA, Thaïs Nívia de Lima. Educação/Instrução. In: Glossário de Termos do Mundo Ibérico Setecentista, 2019b. Disponível em: https://denipoti.wixsite.com/ website. Acesso em: 15 mar. 2020.

FONSECA, Thaïs Nívia de Lima. As vilas na América portuguesa e a emergência da instrução pública (séculos XVIII e XIX). Sarmiento Revista Galego-Portuguesa de História da Educação, Vigo, v. 23, p. 13-30, 2020.

FONSECA, Thaïs Nívia de Lima; SANTOS, Antonio Cesar de Almeida (orgs.). Cultura e educação na América Portuguesa. Belo Horizonte: Editora da UFMG, 2020.

FORMIGA, Francis Albert Cotta. Disciplina (militar). In: Glossário de Termos do Mundo Ibérico Setecentista, 2020. Disponível em: https://denipoti.wixsite.com/ website. Acesso em:14 mar. 2020.

FORMIGA, Francis Albert Cotta. Disciplina militar no império português: práticas educativas e instrução militar na América portuguesa e nas Minas setecentista. Belo Horizonte: UFMG, 2019. Projeto de Dissertação de Mestrado em Educação.

GALVÃO, Ana Maria. História das culturas do escrito: tendências e possibilidades de pesquisa. In: MARINHO, Marildes; CARVALHO, Gilcinei Teodoro (org.). Cultura escrita e letramento. Belo Horizonte: Editora UFMG, 2010. p. 218-248.

GORGULHO, Talitha Maria Brandão. A educação como herança das elites coloniais em três comarcas da Capitania de Minas Gerais: Rio das Mortes, Rio das Velhas e Vila Rica (1756-1809). 2020. Tese (Doutorado em Educação) - Universidade Federal de Minas Gerais, Belo Horizonte, 2020.

HARDEN, Alessandra Ramos Oliveira. Tradução, história e o iluminismo lusobrasileiro: a Casa Tipográfica do Arco do Cego e as línguas do progresso. In: SANTOS, Antonio Cesar de Almeida (org.). Ilustração, cultura escrita e práticas culturais e educativas. Ponta Grossa: Estúdio Texto, 2016, p. 107-130.

HARDEN, Alessandra Ramos Oliveira. Tradução e ciência no iluminismo lusobrasileiro: intertextualidade em epígrafes e divisas. Cadernos de Tradução, Florianópolis, v. 38, n. 3, p. 259-278, 2018.

IM HOF, Ulrich. A Europa no século das Luzes. Lisboa: Editorial Presença, 1995. 
JULIO, Kelly Lislie. "Os têm tratado e educado" - as mulheres e suas ações para a manutenção da família e educação de menores no Termo de Vila Rica, MG (1770 - 1822). 2017. Tese (Doutorado em Educação) - Universidade Federal de Minas Gerais, Belo Horizonte, 2017.

KUHN, Fábio. Um governador “ilustrado" no sul da América portuguesa: José da Silva Pais (1735-1760). In: SANTOS, Antonio Cesar de Almeida (org.). Ilustração, cultura escrita e práticas culturais e educativas. Ponta Grossa: Estúdio Texto, 2016. p. 55-68.

LAGE, Ana Cristina Pereira. Conexões vicentinas: particularidades políticas e religiosas da educação confessional em Mariana e Lisboa oitocentistas. Bauru: Paco Editorial, 2013.

LAGE, Ana Cristina Pereira. Mulheres de véu preto: letramento religioso das irmãs clarissas na América Portuguesa. História Questões e Debates, Curitiba, v. 60, p. 107-131, 2014.

LAGE, Ana Cristina Pereira. Religião católica e instituições educativas na capitania de Minas Gerais. In: FONSECA, Thaïs Nívia de Lima (org.). História da educação em Minas Gerais: da Colônia à República. Uberlândia: EDUFU, 2019a. v. 1, p. 131-152.

LEITÃO, Ana Rita Bernardo. Escrita à Prova ou a Pena por Espada: Manuscritos subversivos e Inquisição Portuguesa (sécs. XVI-XIX). In: COUTO, Edilece Souza et al. (org.). SIMPÓSIO INTERNACIONAL DE ESTUDOS INQUISITORIAIS: NOVAS FRONTEIRAS, 3., 2016, Cachoeira. Anais [...]. Cachoeira: UFRB, 2016. p. 1-21.

LUZ, Itacir Marques da. Laços da diáspora: associacionismo e educabilidade entre a população negra de Pernambuco na primeira metade do século XIX. 2014. Tese (Doutorado em Educação) - Universidade Federal de Minas Gerais, Belo Horizonte, 2014.

MAGALHÃES, Joaquim Romero. A universidade e a inquisição. In: FUNDAÇÃO CALOUSTE GULBENKIAN. História da universidade em Portugal, (1537-1771). Coimbra: Universidade de Coimbra: Fundação Calouste Gulbenkian, 1997. t. 2, v. 1, p. 971-988.

MAGALHÃES, Justino Pereira de. Ler e escrever no mundo rural do antigo regime: um contributo para a história da alfabetização e da escolarização em Portugal. Braga: Universidade do Minho: Instituto de Educação, 1994. 
MAGALHÃES, Justino. O mural do tempo: manuais escolares em Portugal. Lisboa: Edições Colibri: Instituto de Educação da Universidade de Lisboa: UIDEF, 2011.

MAGALHÃES, Justino. O Manual escolar no quadro da história cultural: para uma historiografia do manual escolar em Portugal. Sísifo, Feira de Santana, n. 1, p. 5-14, 2018.

MARTINS, Carlos Moura. A aplicação da ciência à política do território na transição do século XVIII para o século XIX. In: ARAÚJO, Ana Cristina; FONSECA, Fernando Taveira (coord.). A universidade pombalina: ciência, território e coleções científicas. Coimbra: Universidade de Coimbra, 2017. p. 245-312.

MOLANO VEGA, Mario Alejandro. Reinhart Koselleck: historias de conceptos. Conceptos Históricos, San Martin, n. 1, p. 162-181, 2015.

MORAIS, Christianni Cardoso. Posse e usos da cultura escrita e difusão da escola: de Portugal ao Ultramar, Vila e Termo de São João Del Rei, Minas Gerais (17501850). 2009. Tese (Doutorado em História) - Universidade Federal de Minas Gerais, Belo Horizonte, 2009.

MOSCATO, Daniela Casoni. O viajante não está só: a cultura científica em memórias sobre o Brasil e as ligações entre os naturalistas luso-brasileiros do século XVIII e os viajantes cientistas do século XIX. 2017. Tese (Doutorado em História) - Universidade Federal do Paraná, Curitiba, 2017.

OLIVEIRA, Hilton Cesar de. Educar "solteirões extravagantes" para obtenção da família ideal: estratégias oficiais de depuração social - Minas Gerais 1717/1732. Belo Horizonte: UFMG, 2017. Projeto de Pós-Doutorado em História da Educação.

RIPE, Fernando Cezar; AMARAL, Giana Lange do. O dispositivo da cultura escrita na constituição do sujeito infantil moderno: evidências em impressos portugueses (finais do século XVII e século XVIII). Maracanan, Rio de Janeiro, $n$. 16, p. 106-128, 2017.

RODRIGUES, José Damião. Horizontes de reformas e luzes: uma leitura historiográfica a partir da América portuguesa. In: GODOY, Scarlett O’Phelan; RODRÍGUES GARCÍA, Margarita Eva (coord.). El ocaso del Antiguo Régimen em los impérios ibéricos. Lima: Pontificia Universidad Catolica del Perú: CHAM, 2017. p. 167-186.

SANCHES, Antonio Nunes Ribeiro. Cartas sobre a educação da mocidade. Coimbra: 
Imprensa da Universidade, 1922.

SANTOS, Antonio Cesar de Almeida. Aritmética política e a administração do estado português na segunda metade do século XVIII.In: DORÉ, Andréa; SANTOS, Antonio Cesar de Almeida (org.). Temas setecentistas: governos e populações no Império português. Curitiba: UFPR: Fundação Araucária, 2008. p. 143-152.

SANTOS, Antonio Cesar de Almeida. Para a instrução dos homens encarregados dos negócios públicos no final do Antigo Regime português. In: FONSECA, Thaïs Nívia de Lima (org.). As reformas pombalinas no Brasil. Belo Horizonte: Mazza Edições, 2011. p. 205-226.

SANTOS, Antonio Cesar de Almeida (org.). Ilustração, cultura escrita e práticas culturais e educativas. Ponta Grossa: Estúdio Texto, 2016a.

SANTOS, Antonio Cesar de Almeida. A aula de comércio: uma escola política e magnífica para a formação de negociantes peritos e hábeis. CONGRESSO LUSO BRASILEIRO DE HISTÓRIA DA EDUCAÇÃO, 11., 2016, Porto. Atas [...]. Porto: [s. n.], $2016 \mathrm{~b}$.

SANTOS, Antonio Cesar de Almeida. Instruções de governo e práticas ilustradas na América Portuguesa. In: SANTOS, Antonio Cesar de Almeida (org.). Ilustração, cultura escrita e práticas culturais e educativas. Ponta Grossa: Estúdio Texto, 2016c, p. 37-54

SANTOS, Antonio Cesar de Almeida. Poder e territorialização na América portuguesa (segunda metade do século XVIII). Revista de História Moderna, Alicante, n. 36, p. 323-348, 2018.

SANTOS, Antonio Cesar de Almeida. Delimitações introdutórias. Glossário do mundo ibérico setecentista. 2019a. Disponível em: https://denipoti.wixsite.com/ website/sobre-2. Acesso em: 16 abr. 2019.

SANTOS, Antonio Cesar de Almeida. Civil/civilizar/civilização. Glossário do mundo ibérico setecentista. 2019b. Disponível em: https://denipoti.wixsite.com/ website/sobre-2. Acesso em: 16 abr. 2019.

SANTOS, Antonio Cesar de Alveida. Letrados. Glossário do mundo ibérico setecentista. 2019c. Disponível em: https://denipoti.wixsite.com/website/ sobre-2. Acesso em: 18 abr. 2019.

SOUZA, Laura de Mello e. Notas sobre a pedagogia implícita de governadores 
coloniais no século XVIII. In: FONSECA, Thaïs Nívia de Lima; SANTOS, Antonio Cesar de Almeida (org.). Cultura e educação na América portuguesa. Belo Horizonte: Editora UFMG, 2020. p. 35-50.

TAVARES, Rui. Lembrar, esquecer, censurar. Estudos Avançados, São Paulo, v. 13, n. 37, p. 125-154, 1999.

VALADARES, Virginia Maria Trindade. A maçonaria moderna nas malhas do Santo Ofício no Império Português no setecentos. Revista de História Regional, Ponta Grossa, v. 19, n. 2, p. 346-360, 2014.

VARTULI, Silvia Maria A. Rachi. Redigir a intimidade: escrita mediada e relações sociais na América portuguesa. Revista de História Regional, Ponta Grossa, v. 19, n. 2, p. 327-345, 2014.

VARTULI, Silvia Maria A. Rachi. Por mãos alheias: usos da escrita na sociedade colonial. Belo Horizonte: Editora PUCMinas, 2016.

VENTURI, Franco. Utopia e reforma no Iluminismo. Bauru: EDUSC, 2003.

VILLALTA, Luiz Carlos. A Universidade de Coimbra sob o reformismo ilustrado português (1770-1807). In: FONSECA, Thaïs Nívia de Lima (org.). As reformas pombalinas no Brasil. Belo Horizonte: Mazza Edições, 2011. p. 157-202.

\section{Notas}

${ }^{1}$ Departamento de História, Universidade Federal do Paraná.

${ }^{2}$ Departamento de História, Universidade Estadual de Londrina.

${ }^{3}$ Departamento de Ciências Aplicadas à Educação, Universidade Federal de Minas Gerais.

${ }^{4} \mathrm{O}$ Grupo tem como líderes os professores Thais Nívia de Lima e Fonseca (UFMG) e Antonio Cesar de Almeida Santos (UFPR). O professor Cláudio Denipoti (UEL) é o responsável pela política de publicações do Grupo.

${ }^{5}$ Desde 2010, foram financiados onze projetos coletivos (Editais Universal e Ciências Humanas do CNPq e da FAPEMIG).

${ }^{6}$ Algumas publicações estão disponíveis em Ceibero (2020).

${ }^{7}$ Lembramos que Espanha e América espanhola só passaram a constituírem-se objetos de estudo do Grupo muito recentemente.

${ }^{8}$ Integram a Linha de Pesquisa Administração, instrução e educação os pesquisadores Antonio Cesar de Almeida Santos e Eduardo Teixeira de Carvalho Júnior.

${ }^{9}$ Ana Cristina Araújo, da Universidade de Coimbra, é autora de diversos textos nos quais discute a "filosofia das Luzes no mundo português", com especial ênfase no contexto das 
reformas dos Estatutos da Universidade (Ver ARAÚJO, 2000).

${ }^{10}$ Ainda que não integre esta Linha de Pesquisa, Verona Segantini, em texto apresentado adiante nesta seção, mostra como se deu esse aproveitamento das novas "ciências" ensinadas na Universidade no aparato administrativo luso.

${ }^{11} \mathrm{Na}$ redação desta seção do artigo, levou-se em conta o texto inédito produzido no âmbito dos debates do CEIbero ao longo da última década intitulado Cultura escrita, redigido por Álvaro Antunes, Ana Rita Leitão, Ana Cristina Lage, Cláudio DeNipoti, Justino Magalhães e Silvia Vartuli.

${ }^{2}$ Esta linha inclui os pesquisadores Álvaro Antunes, Alessandra Harden, Cláudio DeNipoti, Christianni Cardoso Morais, Daniela Casoni Moscato e Fernando Cezar Ripe da Cruz.

${ }^{13}$ Álvaro Antunes, em artigo publicado nesta seção, retoma com maiores detalhes a discussão acerca de cultura escrita e cultura do escrito, buscando avaliar as potencialidades analíticas destes conceitos.

${ }^{14}$ Pesquisadores da linha Instituições e práticas culturais e educativas: Ana Cristina Pereira Lage, Itacir Marques da Luz, Fabrício Vinhas Manini Angelo, Francis Albert Cotta Formiga, Hilton Cesar de Oliveira, Jane Elisa Otomar Buecke, Kelly Lislie Julio, Silvia Maria Rachi Vartuli, Talitha Maria Brandão Gorgulho, Thais Nívia de Lima e Fonseca, Verona Campos Segantini, Virginia Maria Trindade Valadares.

${ }^{15}$ Ver, na Bibliografia, os trabalhos de: Fonseca (2009, 2016a, 2016b, 2019b), Julio (2017), Angelo (2017), Gorgulho (2020), Vartuli (2016), Oliveira (2017).

${ }^{16} \mathrm{O}$ Artigo de Kelly Lislie, apresentado nesta seção, traz uma interessante discussão sobre a posse de livros e as representações construídas acerca deste objeto cultural.

${ }^{17}$ Ana Cristina Lage, no artigo publicado nesta seção, discute as especificidades de conventos e de recolhimentos femininos instalados na América portuguesa, buscando compreender as escolhas das mulheres que ingressavam nestes espaços institucionais educativos.

${ }^{8}$ Embora trabalhando com outro recorte temporal, Justino Magalhães, também em texto que compõe esta seção, apresenta uma discussão conceitual sobre as relações entre educação, instituições educativas e processos de civilização nos "sertões" brasileiros.

${ }^{19}$ Basicamente, a documentação utilizada consiste em legislação, papeis administrativos de várias instâncias, papeis privados, produção intelectual de cunho moral e político, manuscritos ou impressos.

${ }^{20}$ Este tipo de estudos pode ser observado no texto de Eduardo Carvalho Júnior publicado nesta seção. Sua atenção está voltada para o uso do termo boa razão no século XVIII português. 